\title{
sciendo SIGNIFICANCE ANALYSIS OF SHIP OPERATIONAL STATES AS \\ A FACTOR INFLUENCING \\ THE ENERGY EFFICIENCY OF \\ A RESEARCH - TRAINING VESSEL
}

DOI 10.2478/ntpe-2018-0028

\author{
Assoc. Prof. Cezary Behrendt, PhD. \\ MSc. Katarzyna Prill \\ Maritime University of Szczecin, Poland \\ Ing. Marek Patsch, PhD \\ University of Zilina, Slovak Republic
}

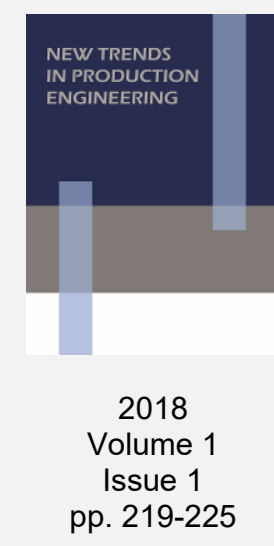

\begin{abstract}
Ship operational state is a sequence of temporary values of state variable parameters expressing the properties of a particular object and which are recognised as significant for a specific problem. They are the key elements of the operational tasks and essential to determining the Energy Efficiency Operational Indicator for a specialised vessel. In that case, the method refers directly to specific operational states and their significance for a particular operational task in the time function. Based on the surveys conducted on a population of people employed by the ship owner and involved in the ship operation, one has analysed the significance of the operational states for that vessel. The differentiated perception of the operational states of the subjected vessel results from, inter alia, the tasks performed by the responders as their duties, their experience and the level of their engagement in the ship operation. A qualitative and quantitative analysis of the states enables to conduct the planning process in terms of operational tasks of the specialized ship for effective and efficient operation.
\end{abstract}

Keywords: operational state, special vessel energy efficiency

\section{INTRODUCTION}

The variety of transported goods, the composition and number of research teams, and training groups, as well as a wide range of research services provided determine the research training vessels' specialization. The specialization depends directly on the tasks to be performed. Although there is no one uniform, global list of commonly used definitions referring to the types of vessels, their particular names and descriptions are implemented into the international law, in particular in the IMO conventions such as the SOLAS, the MARPOL or the STCW (SOLAS, 2014, MARPOL, 2017, STCW, 2017, IMO, 2018). During the literature studies, one may encounter a number of various divisions and classifications of ships developed and adopted by classification societies (Polish Register of Shipping, 2017). The ships' classification depends directly on the criterion such as e.g. a type of water at which the ship travels. In this category, one may distinguish between seagoing vessels and inland vessels. As a further exemplary criterion, the type of sailing may be listed. In that case, the following types of navigation may be mentioned: unlimited navigation, limited navigation, coasting, harbour service, etc. The other classification refers to the arrangement per drive type (e.g. motor vessels, sailing vessels etc.). Further criteria include the type of material that the hull is made of, thruster type or shipping type (liner, tramping, shuttle etc.) (Christiansen et al. 2013). However, the most popular classification, that is commonly applicable both by the classification societies and maritime administration, is the one as per what the ship was designed to. One of the groups in that classification refers to transport ships. Another group of ships includes passenger ships. There is also a group of fishing vessels, pleasure ships e.g. yachts and ships used for military purposes. The other category consists of constructions designed to the seabed and sea depth inspections, and exploitation of the natural resources e.g. drilling platforms and platforms for natural gas exploitation. The last group in the classification according to the purpose of the ship are specialized vessels. Lützen at al. 
(Lützen at al. 2017) in their elaboration classified ships in terms of the operation mode into two groups: ships transporting goods and people, and ships performing specialised tasks. As an example, they provided an offshore vessel. The study includes also an analysis of the operation methods for both groups and a comparison of the operational states during the operations of those vessels (Lützen at al., 2017). Sowa A. defines an operational state as descriptive attribute defining the phase of the exploitation process, i.e. the phase of using or operating the object (Sowa, 2012).

The ships' classification in terms of their purpose may be used to demonstrate the differences relating to the occurrence of operating states and their combination in the course of the task performed in relation to a given type of ship. The International Maritime Organisation, in order to define the tools to reduce $\mathrm{CO}_{2}$ emitted to the atmosphere, used the categorization of ships with regard to their purpose, and more specifically to the type of transported cargo. This philosophy may be observed in the IMO MEPC 1.Circ.684 (MEPC, 2009), that includes a list of ships' types for which the tools are recommended, or in MEPC 1.Circ.212(63) (IMO, 2009) and (Chi at al.,2018) which are applied to establish the energy efficiency for new ships. The scheme for the selection of ship types was dictated primarily by the percentage share of these types of ships in the world tonnage (EQUASIS, 2016) and the fact that all of them are transport vessels. Additionally, in the case of transport vessels, it is much easier to specify the $\mathrm{CO}_{2}$ emission on the grounds of the fuel consumption due to the relation of the quantified level of energy efficiency to the mass of the transported cargo or the number of passengers (IMO, 2009). In the case of specialised vessels, as rightly proved by Lützen at al. ((Lützen at al., 2017), the situation becomes less clear as a result of the diversity of the vessels in terms of construction, operation and different priorities of a shipowner or a charterer. Currently, the authors have been carried out a research related to the development of the method for determining the energy efficiency of a specialised vessel, based on the operational states of a ship (Prill and Igielski, 2017). Therefore, the significance level for a given operational state should be determined by the shipowner as it is a key element in the definition of EEOI for a specialised vessel.

The first section of the paper includes the presentation of a research object namely a training research vessel of specialised vessels group. The operational states are defined there, too. The second section presents the research methodology in terms of providing an answer to the question regarding the significance level of a given operational state from the shipowner's point of view. The section covers also the descriptions of the functions of the employed individuals who have an impact on the ship operation. The third section presents the research results, quantitative and qualitative analysis of the results. It also includes the conclusions for further discussion.

\section{CHARACTERISTIC OF A SELECTED REASEARCH - TRAINING VESEEL}

The specialised vessels belong to the group of vessels that constitutes around $35 \%$ of the global number of ships and covers around $1 \%$ of the worldwide tonnage (EQUASIS, 2016). This group includes the ships which in most cases were designed and constructed to perform specific operational tasks (fire-fighting vessels, cable layer vessels, pilot boats, etc.). A representative of this group is a research - training vessel indicated by the authors as a research object. This is a vessel owned by the university whose teaching, training and practice programme is compliant with the requirements of IMO regulations.

The main tasks of the said vessel cover students' maritime training in the engine and the deck department, and research and other commissioned works. The vessel is $60.21 \mathrm{~m}$ long, its beam equals to $10.5 \mathrm{~m}$ and the capacity is $1208 \mathrm{GT}$. It is licensed to navigate in unlimited waters. The vessel may take on board, apart from 11 permanent crew members, maximum 36 students, and scientists in addition to perform, training and research in the scope of hydrographic surveys (MUS, 2018).

For the purpose of the research, the following operational states for the research object were established:

- Manoeuvres, 
- Maritime training - the implementation of the maritime training programme, in particular manoeuvring practice,

- Passage,

- Research, commissioned works,

- Drift,

- Anchoring (no operational tasks being performed,

- Anchoring (operational tasks being performed e.g. trainings, practices with students, alarms),

- Harbour (no operational tasks being performed),

- Harbour (operational tasks being performed e.g. trainings, practices with students, alarms etc.).

The operational states were defined on the basis of the analysis of the ship's purpose and the actual operational data obtained from the Ship Logbooks, taking into account, in particular, the execution of the basic tasks indicated by the shipowner.

\section{RESEARCH METHOLOGY}

In order to determine and specify the significance of the operational states for the research object, a survey was carried out among the 12 individuals employed at the university. They constituted a population within the shipowner organisation having an impact on the operational tasks. The survey process had been preceded by a series of interviews (around $30 \mathrm{~min}$. each) with the individuals. The goal of the interview was to qualify the particular person to a given group of processes carried out along with the execution of the operational tasks. Based on the interviews, the following processes were identified:

1. Supervision process - This process covers the supervision over the research object as a whole, its functioning, technical condition and the supervision over the crew composition. Only one function was assigned to that process, which is the highest one in the shipowner's organizational chart.

2. Planning process - This process includes planning of the operational tasks such as students' training and practises, scientific research and commissioned works. 4 persons were assigned to that process. They were employed at the managerial positions and they were responsible for planning the students' training in the deck department and in the engine department on the research - training vessel. Their responsibly also covered planning in terms of scientific research and commissioned works on the research object.

3. Organisation process - This process includes all the activities related directly to the preparation of the vessel to the operation, proper provision of resources necessary to perform the planned and scheduled operational tasks. There were 4 individuals assigned to this process.

4. Execution process - This process covers direct execution of the planned and scheduled operational tasks. 3 functions at the vessel were assigned to it. The functions are managerial positions from both departments (the engine department and the deck department).

Upon having the processes identified and assigned to the specific positions and functions, a survey was carried out. For the survey purpose, the elements of the Delphi method with target screening was applied.

The significance level of operational states was specified in the survey within the range from 1 to 5 , where 1 means the most significant operational state and 5 refers to the least significant one. There were indicated 9 previously defined operational states for the research object. The survey included also a request to the responders for a voluntary, short descriptive explanation of the motives for the evaluation of individual operational states.

\section{SURVEY RESULTS ANALYSIS}

The survey results were analysed in terms of quantification of the significance of a given operational state by the shipowner representatives and in the view of the factors determining 
the definition of same. An extract from the research analysis is included in the following section of the paper.

\section{Detailed analysis of the survey results}

Figure 1 and Figure 2 present the results of the significance of two selected operational states namely "entry into the harbour and exit from the harbour" and "stay in the harbour".

It may be noticed that for the operational state "manoeuvres" (Fig. 1) very high significance was indicated. 8 people decided to assess this state as 1 i.e. as having the highest significance, while two persons specified that state as less significant and marked it 5 .

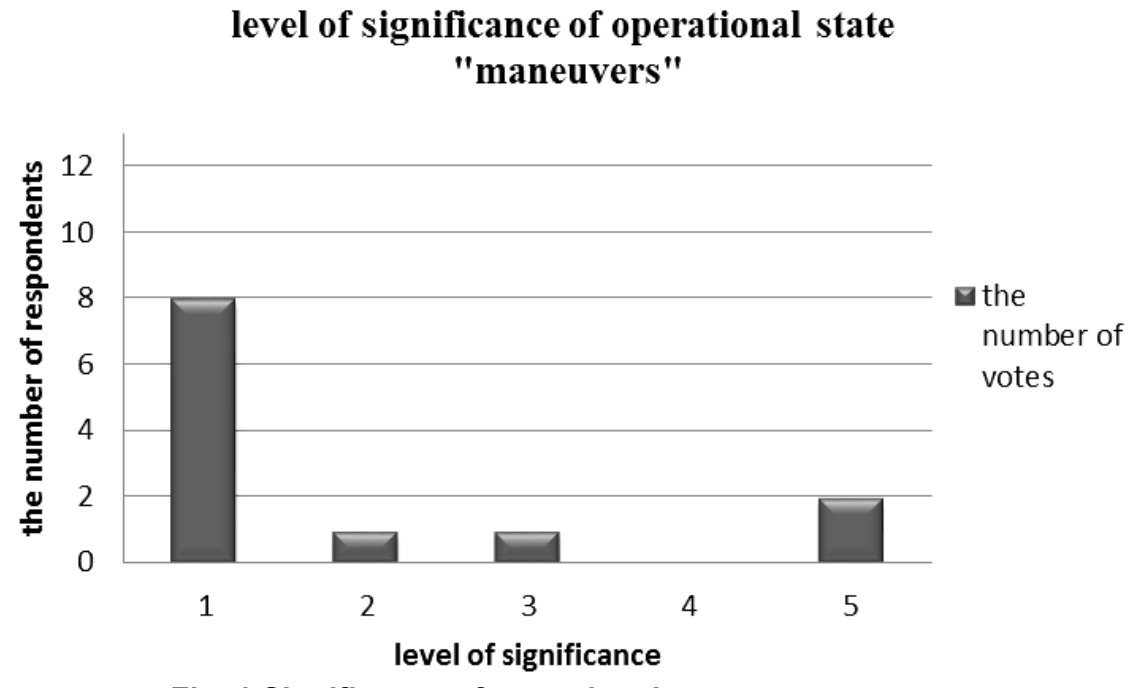

Fig. 1 Significance of operational state - manoeuvres.

Source: Authors' elaboration.

Additionally, two individuals evaluated it at the second and third level of significance. Given the answers provided in the second, descriptive section of the survey, it was detailed that the significance of the said state had been assessed at the highest level due to the fact that the state is "the state with an increased risk of occurrence and is an event directly affecting the reduction of the vessel safety level" or is "one of the most important operational elements, a recurring element and one of the most dangerous operational states at the same time", or is "the most important operational state when every navigation and engine room devices and machines are in the operation". Another argument for the significance level indicated by the responders, who were responsible for the process planning and organizing, was the possibility to learn about the voyage preparatory activities and the ship procedures that are "the substantial part of the maritime training". The performance and duration of the said state also affect research significantly. It was stated that "efficiently completed maneuvers allow for spending more time on research". In cases when the significance of the said state was marked as low, the responders were motivated by the financial aspect i.e. as a result of the increased fuel consumption, a shipowner incurs higher operational costs.

Figure 2 presents the analysis results of the significance of the operational state "harbour without training and exercises" during which no activities related to the operational task are performed.

It may be notices that a low significance was assigned to the operational state "harbour without training and exercises ". Five persons indicated that the state should be assessed as the least important. Four people evaluated it as of medium importance. Additionally, three individuals assigned the first, second and third level of significance accordingly.

Given the answers provided in the second, descriptive section of the survey, it was detailed that the significance level of the said operational state is low due to: "no operational tasks being performed" and "the students' training being carried out at the minimum level". The high significance level of this state, i.e. at the level of 1 and 2 , was assigned by the representatives 
of the groups related to the organisation and ship exploitation processes. In those cases, the responders were driven by the financial aspect and the possibility to carry out technical inspections and repairs that cannot be done in other operational states.

\section{level of significance of operational state \\ "harbour without training and exercises"}

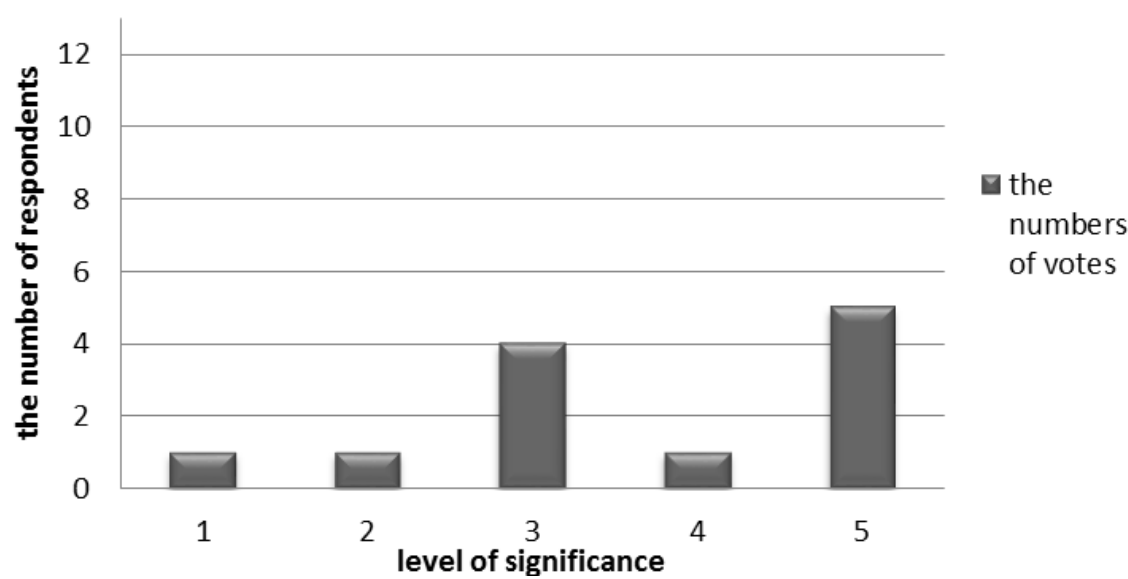

Fig. 2. Significance of operational state - "harbour without training and exercises". Source: Authors' elaboration

The responders indicated the following significance levels of the operational states for the research - training vessel (Table 1).

Table 1.

Significance levels of operational states for the research - training vessel.

\begin{tabular}{|c|l|c|}
\hline Item & \multicolumn{1}{|c|}{ Operational state } & Significance level \\
\hline $\mathbf{1}$ & Manoeuvres & $\mathbf{1}$ \\
\hline $\mathbf{2}$ & Maritime training & $\mathbf{1}$ \\
\hline $\mathbf{3}$ & Passage & $\mathbf{1}$ \\
\hline $\mathbf{4}$ & Research, commissioned works & $\mathbf{3}$ \\
\hline $\mathbf{5}$ & Anchoring (without training or exercises) & $\mathbf{5}$ \\
\hline $\mathbf{6}$ & Anchoring (with training or exercises) & $\mathbf{2}$ \\
\hline $\mathbf{7}$ & Harbour (without training or exercises) & $\mathbf{5}$ \\
\hline $\mathbf{8}$ & Harbour (with training or exercises) & $\mathbf{3}$ \\
\hline $\mathbf{9}$ & Drift & $\mathbf{3}$ \\
\hline
\end{tabular}

Source: Authors' elaboration

\section{DISCUSSION}

The responders stated that the operational states of the highest significance are entry and exit manoeuvres, maritime training and passage. While stay at anchoring and stay in the harbour without training performed were indicated as the least significant due to no operational tasks being performed. A graphic illustration of the survey results is presented in Figure 3 . The Figure includes a summary of operational states of the selected vessel and the significance levels specified by the responders. 
Level of the significance of the operatonal states

of reaserch - training vessel

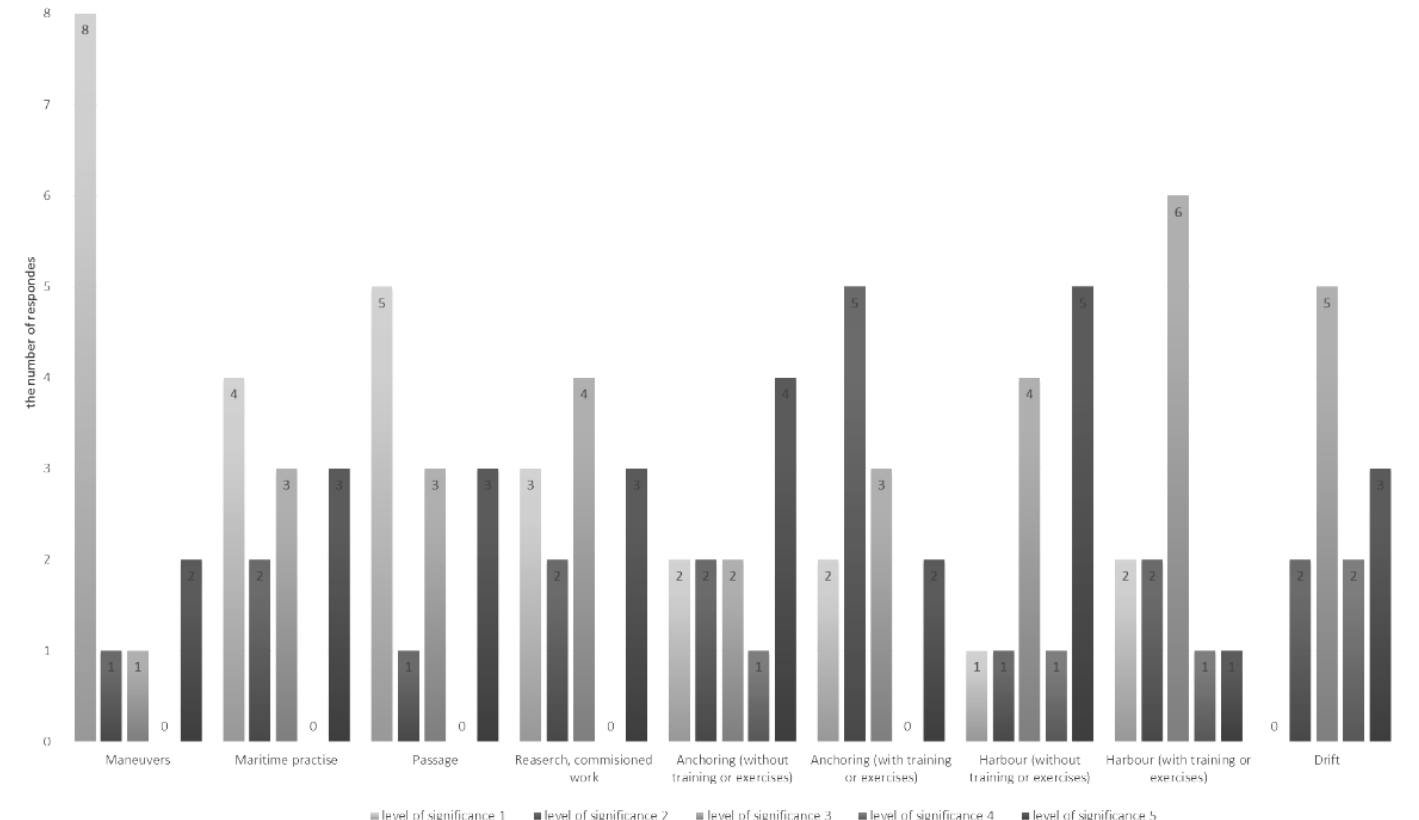

Fig. 3. Summary of operational states of the selected vessel and the significance levels. Source: Authors' elaboration.

\section{CONCLUSION}

A lot of people are involved in the operation of the specialised vessel on behalf of the shipowner. They considered that the operational states' significance varied. The differences resulted mainly from the nature of the tasks and duties that the person carried out and from the responsibilities arising from the processes. It should be highlighted that the vessel operational states which do not reflect directly any commissioned operational tasks or generate financial losses for the shipowner were assessed by their representatives as not as significant. The quantitative and qualitative analysis of the operational states' significance for the research object indicated the possibility to apply the method as a supportive tool for the planning process in terms of effective operation. However, it is advisable to perform further analysis of the matter having regard to a potential correlation of the significance level of the operating states in a given operational task and the quantified level of the ship energy efficiency.

\section{ACKNOWLEDGEMENTS}

This research outcome has been achieved under the research project no. 2/S/IESO/2018 financed from a subsidy of the Polish Ministry of Science and Higher Educations for statutory activities of Maritime University of Szczecin.

\section{REFERENCES}

Chi, H., Pedrielli, G., Ng, S.H., Kister, T. and Bressan, S., (2018) A framework for real-time monitoring of energy efficiency of marine vessels, Energy, 145, pp. 246-260.

Christiansen, M., Fagerholt K., Nygreen B., and Ronen D., (2013) Ship routing and scheduling in the new millennium, European Journal of Operational Research, 228 pp.467-483.

EQUASIS (2016). The world merchant fleet in 2016, [online]. Available at: http://www. equasis .org/ Fichiers/Statistique/, [Accessed: 15.Mar.2018].

IMO.org,(2018) IMO Official Website. [online] Available at: [Accessed: 15.Mar.2018].

Lützen M., Mikkelsen L.L., Jensen S., and Rasmussen H.B. (2017). Energy Efficient of working vessels - A Framework, Journal of Cleaner Production, 143, pp. 90-99.

MARPOL (2017). International Convention for Prevention of Pollution from Ships (MARPOL) 1973 consolidated edition 2017, IMO, ISBN 978-92-801-16571. 
MEPC 1./Circ.684. (2009). Guidelines for voluntary use of the ship energy efficiency operational indicator (EEOI).

MEPC 1./Circ.212(63), (2012) Guidelines on the method of calculation of the attained energy efficiency design index (EEDI) for new ships.

am.szczecin.pl (2018). Maritime University of Szczecin official website. [online], Available at: http://statek.am.szczecin.pl/. [Accessed: 06.Mar.2018].

PRS (2017). Polish Register of Shipping Register of ships 2017. [online]. Available at: https://www.prs.pl/_files/parent519/rejestr_mor_2017.pdf, [Accessed: 15.Mar.2018].

Prill, K., Igielski, K., (2017) Calculation of operational indicator EEOI for ships designed other purpose than transport based on a research-training vessel, XVI/XIII International Scientific and Technical Conference. Protection of man in the work environment, servicing of machines and devices. Integrated management systems: Quality - Environment Safety - Technology, OMiUO, Poland, 5-8 October 2017.

SOLAS (2014). International Convention for safety of life at sea (SOLAS) 1978, consolidated edition 2014 IMO, ISBN 978-92-801-15949.

Sowa A. (2012). Object state as ambiguous term in contemporary technical operation, Mechanics - Technical Transactions, 7-M/2012 14 (109) pp. 269-278.

STCW (2017). International Convention on standards of Training and Watchkeeping for Seafarers (STCW) 1978, consolidated edition 2017, IMO, ISBN 978-92-801-16359.

Date of submission of the article to the Editor: 05/2018

Date of acceptance of the article by the Editor: 09/2018 